\title{
Performance computation of window air conditioner with very low GWP near azeotropic refrigerant mixtures as a drop in Substitutes to R22
}

\author{
Shaik Sharmas Vali ${ }^{*}$, Talanki Puttaranga Setty ${ }^{1}$ Ashok Babu ${ }^{1}$ \\ ${ }^{1}$ National Institute of Technology Karnataka Surathkal, Mechanical Engineering Department, \\ Mangalore-575025, INDIA.
}

\begin{abstract}
The principal objective of the present study is to compute the thermodynamic performance of window air conditioner based on standard vapour compression refrigeration cycle using R22, R407C and nineteen refrigerant mixtures. In this work nineteen R290/R1270 blends at different compositions are developed. A MATLAB code is developed to compute the thermodynamic performance parameters of all the studied refrigerants at condensing and evaporating temperatures of $54.4^{\circ} \mathrm{C}$ and $7.2^{\circ} \mathrm{C}$ respectively. The performance parameters are cooling effect, compressor work, COP, compressor discharge temperature, power per ton of refrigeration and volumetric cooling capacity respectively. Analytical results revealed that COP of new binary mixture R290/R1270 (90/10 by mass \%) is $2.82 \%$ higher among $\mathrm{R} 22, \mathrm{R} 407 \mathrm{C}$ and nineteen studied refrigerants. Energy required by the compressor per ton of refrigeration for $\mathrm{R} 290 / \mathrm{R} 1270$ (90/10 by mass \%) is $2.73 \%$ lower among R22, R407C and nineteen studied fluids. The discharge temperature of the compressor for all the nineteen investigated blends are reduced by $6.0-8.9 \mathrm{oC}$ compared to R22. Overall thermodynamic performance of window air conditioner with R290/R1270 (90/10 by mass \%) is better than R22 with significant savings in energy consumption and hence it is an energy efficient ecofriendly refrigerant mixture as a drop in substitute to R22.
\end{abstract}

Keywords: COP; Discharge temperature; GWP; Ecofriendly: Energy savings; R290/R1270 blends

\section{Introduction}

Hydrochlorofluorocarbon (HCFC) refrigerant R22 was extensivenly used in air conditioning as well as heat pump industries from past several years. Since R22 has better thermophysical and thermodynamic properties. But R22 contains ozone layer desctruction substance called chlorine. Therefore R22 was eventually phase out in all the developed nations by the year 2030 as per Monetreal protocal [1-3]. Till now no pure refrigerant is avialble to replace R22. Therefore it is essential to develop new ecofriendly refrigerant blends. Earlier several theoretical and expermintal investigations were carried to find an appropriate fluid to replace R22. From the past several years refrigerants R407C and R410A were the foremost substitues to R22 [4]. Theorotical results reported that R444B was a viable refrigerant to replace R22 [5]. Experimental results reported that R407C was a suitable retrofit candidate to R22 [6]. Experimental test was conducted in an air conditioner with R290 as a drop in refrigerant. Test results exhibited that performance of R290 was 2.8-

*Corresponding author: sharmasvali.nitk@gmail.com 
7.9\% higher than R22 [7]. Experimental tests revealed that the ternary refrigerant mixture R32/R125/R161 (15/34/51 by weight percentage) was suitable choice to replace R407C. Since COP of above mixture was better than R407C [8]. Experimental studies reported that performance of binary mixture R170/R290 (4/96 by mass \%) was similar to that of performance of R22 [9]. A detailed review paper suggested that hydrocarbons and its blends were most suitable candidates to air conditioning and refrigeration sectors [10]. Experimental studies were conducted in a heat pump apparatus with R22 and binary blend R431A (R290/R152a 71/29 by mass \%) used for heat pump and air conditioning applications. Test results exhibited that COP of R431A was 3.5-3.8\% superior than R22 [11]. Performance tests were done in a heat pump equipment with R22 and binary blend R432A (R1270/RE170 80/20 by mass \%) used for heat pump and air conditioning applications. Experimental results showed that performance of R432A was $8.5-8.7 \%$ superior than the R22 [12]. Experimental investigations were carried out in a heat pump device with R22 and binary blend R433A (R1270/R290 30/70 by mass \%) used for heat pump and air conditioning applications. Test results revealed that performance of R433A was 4.9-7.6\% superior than R22 [13]. The present study mainly focuses on finding an alternative refrigerant to replace R22. For this thermodynamic performance computation of nineteen refrigerant blends (R290/R1270) is carried out based on standard vapour compression refrigeration system.

\section{Properties of refrigerants}

In the present study apart from $\mathrm{R} 22$ and $\mathrm{R} 407 \mathrm{C}$, total nineteen refrigerant blends (R290/R1270) of various compositions are developed. All the nineteen binary refrigerant blends R290/R1270 (Refrigerants 2 to 20 as given in table 2) are closer to azeotropic in nature. Since their temperature glide is less than $0.5 \mathrm{oC}$. A MATLAB code is developed to compute the thermodynamic properties of refrigerants like R22, R407C and R290/R1270 blends by using Martin-Hou equation of state [14]. Since thermodynamic properties of considered refrigerants are useful for the computation of thermodynamic performance of an air conditioner.

$$
\begin{gathered}
P=\frac{R T}{v-b}+\frac{a_{2}+b_{2} T+c_{2} e^{\frac{-5.475 T}{T_{C}}}}{(v-b)^{2}}+\frac{a_{3}+b_{3} T+c_{3} e^{\frac{-5.475 T}{T_{C}}}}{(v-b)^{3}}+\frac{a_{4}}{(v-b)^{4}} \\
+\frac{b_{5} T}{(v-b)^{5}}
\end{gathered}
$$

The computed properties of R22 and R407C shows good agreement with the experimental reported properties available in ASHRAE fundamental data hand book. The deviation of computed properties of R22 and R407C from that of ASHRAE is within 2 to $4 \%$ for the given operating conditions. Therefore the developed MATLAB code is reliable and hence it can be used for the development of thermodynamic properties of other new refrigerant blends. The properties of new refrigerants blends (R290/R1270) are not available in literature and hence they are not compared. However properties of refrigerant R290/R1270 blends are compared with REFPROP. The deviation of properties from that of REFPROP is within 1.5 to $4 \%$ for the given working conditions. Hence the same developed thermodynamic properties are used in the thermodynamic analysis. The code followed for the refrigerants is given in table 1 and the basic physical and critical properties of R22, R407C and nineteen refrigerant blends (R290/R1270) taken from REFPROP is given below in table 2 respectively[15]. 
Table 1. Code of the refrigerants

\begin{tabular}{|cc|c|}
\hline \multicolumn{1}{|c|}{ Refrigerant code } & Composition (by mass \%) \\
\hline \multicolumn{2}{|c|}{1 (R22) } & Pure fluid \\
\hline 2 & $(\mathrm{R} 290 / \mathrm{R} 1270)$ & $5 / 95$ \\
\hline 3 & $(\mathrm{R} 290 / \mathrm{R} 1270)$ & $10 / 90$ \\
\hline 4 & $(\mathrm{R} 290 / \mathrm{R} 1270)$ & $15 / 85$ \\
\hline 5 & $(\mathrm{R} 290 / \mathrm{R} 1270)$ & $20 / 80$ \\
\hline 6 & $(\mathrm{R} 290 / \mathrm{R} 1270)$ & $25 / 75$ \\
\hline 7 & $(\mathrm{R} 290 / \mathrm{R} 1270)$ & $30 / 70$ \\
\hline 8 & $(\mathrm{R} 290 / \mathrm{R} 1270)$ & $35 / 65$ \\
\hline 9 & $(\mathrm{R} 290 / \mathrm{R} 1270)$ & $40 / 60$ \\
\hline 10 & $(\mathrm{R} 290 / \mathrm{R} 1270)$ & $45 / 55$ \\
\hline 11 & $(\mathrm{R} 290 / \mathrm{R} 1270)$ & $50 / 50$ \\
\hline 12 & $(\mathrm{R} 290 / \mathrm{R} 1270)$ & $55 / 45$ \\
\hline 13 & $(\mathrm{R} 290 / \mathrm{R} 1270)$ & $60 / 40$ \\
\hline 14 & $(\mathrm{R} 290 / \mathrm{R} 1270)$ & $65 / 35$ \\
\hline 15 & $(\mathrm{R} 290 / \mathrm{R} 1270)$ & $70 / 30$ \\
\hline 16 & $(\mathrm{R} 290 / \mathrm{R} 1270)$ & $75 / 25$ \\
\hline 17 & $(\mathrm{R} 290 / \mathrm{R} 1270)$ & $80 / 20$ \\
\hline 18 & $(\mathrm{R} 290 / \mathrm{R} 1270)$ & $85 / 15$ \\
\hline 19 & $(\mathrm{R} 290 / \mathrm{R} 1270)$ & $90 / 10$ \\
\hline 20 & $(\mathrm{R} 290 / \mathrm{R} 1270)$ & $95 / 5$ \\
\hline (R407C R32/R125/R134a) & $23 / 25 / 52$ \\
\hline
\end{tabular}

Table 2. Basic physical and environmental properties of investigated refrigerants

\begin{tabular}{|c|c|c|c|c|c|c|c|}
\hline $\begin{array}{c}\text { Refrigerant } \\
\text { code }\end{array}$ & $\begin{array}{c}\mathbf{M} \\
(\mathbf{k g} / \mathbf{k m o l})\end{array}$ & $\begin{array}{c}\mathbf{T}_{\mathbf{b}} \\
\left(\mathbf{(}^{\mathbf{C}} \mathbf{C}\right)\end{array}$ & $\begin{array}{c}\mathbf{P}_{\mathbf{c}} \\
\mathbf{( \mathbf { M p a } )}\end{array}$ & $\begin{array}{c}\mathbf{T}_{\mathbf{c}} \\
\mathbf{( K )}\end{array}$ & $\mathbf{O D P}$ & $\begin{array}{c}\mathbf{G W P} \\
(\mathbf{1 0 0} \text { years) }\end{array}$ & $\begin{array}{c}\mathbf{T}_{\mathbf{g}} \\
\left({ }^{\mathbf{}} \mathbf{C}\right)\end{array}$ \\
\hline 1 & 86.5 & -40.81 & 4.99 & 369.3 & 0.055 & 1760 & 0 \\
\hline 2 & 42.176 & -47.45 & 4.538 & 364.3 & 0 & $<3$ & 0.03 \\
\hline 3 & 42.273 & -47.27 & 4.521 & 364.4 & 0 & $<3$ & 0.05 \\
\hline 4 & 42.37 & -47.07 & 4.505 & 364.5 & 0 & $<3$ & 0.09 \\
\hline 5 & 42.468 & -46.85 & 4.490 & 364.7 & 0 & $<3$ & 0.13 \\
\hline 6 & 42.566 & -46.62 & 4.475 & 364.9 & 0 & $<3$ & 0.16 \\
\hline 7 & 42.665 & -46.37 & 4.460 & 365.1 & 0 & $<3$ & 0.21 \\
\hline 8 & 42.764 & -46.11 & 4.445 & 365.3 & 0 & $<3$ & 0.25 \\
\hline 9 & 42.864 & -45.84 & 4.431 & 365.6 & 0 & $<3$ & 0.29 \\
\hline 10 & 42.964 & -45.56 & 4.417 & 365.9 & 0 & $<3$ & 0.32 \\
\hline 11 & 43.064 & -45.27 & 4.403 & 366.2 & 0 & $<3$ & 0.35 \\
\hline 12 & 43.165 & -44.97 & 4.388 & 366.5 & 0 & $<3$ & 0.37 \\
\hline 13 & 43.267 & -44.67 & 4.374 & 366.8 & 0 & $<3$ & 0.38 \\
\hline 14 & 43.368 & -44.36 & 4.360 & 367.2 & 0 & $<3$ & 0.39 \\
\hline 15 & 43.471 & -44.04 & 4.345 & 367.5 & 0 & $<3$ & 0.38 \\
\hline 16 & 43.574 & -43.73 & 4.330 & 367.9 & 0 & $<3$ & 0.35 \\
\hline 17 & 43.677 & -43.41 & 4.315 & 368.3 & 0 & $<3$ & 0.31 \\
\hline 18 & 43.781 & -43.08 & 4.299 & 368.7 & 0 & $<3$ & 0.27 \\
\hline 19 & 43.885 & -42.76 & 4.284 & 369.1 & 0 & $<3$ & 0.19 \\
\hline 20 & 43.99 & -42.44 & 4.267 & 369.4 & 0 & $<3$ & 0.10 \\
\hline 21 & 86.204 & -43.63 & 4.631 & 359.3 & 0 & 1774 & 7.0 \\
\hline
\end{tabular}




\section{Thermodynamic performance methodology}

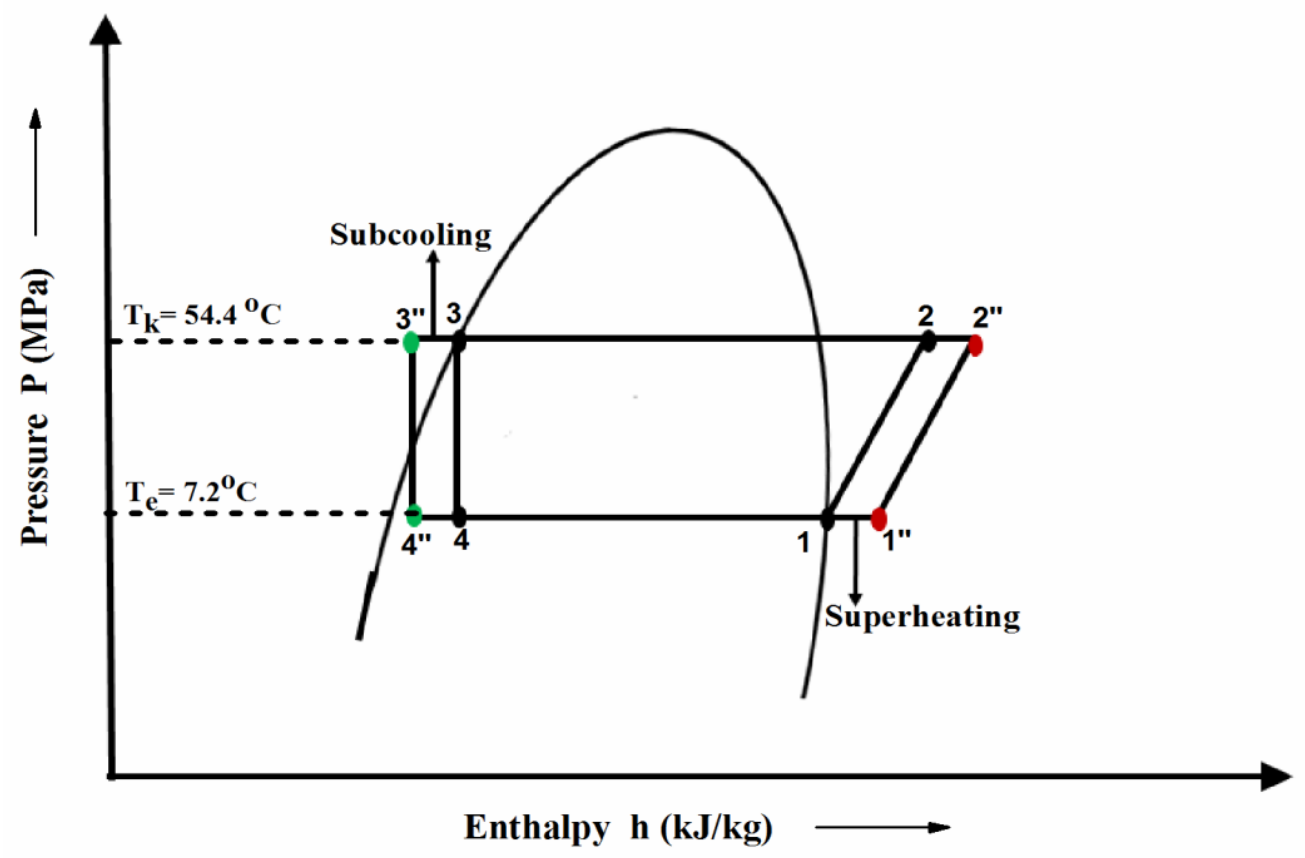

Fig 1. P-h diagram of standard vapour compression refrigeration cycle.

Computational thermodynamic analysis of R22, R407C and nineteen refrigerant blends (R290/R1270) is done based on standard vapour compression refrigeration cycle. The p-h diagram of corresponding cycle is shown in figure 1 [16-17]. In this methodology the various pressure losses and heat losses or heat gains occurred at the various components of the system are ignored. The degree of superheating and subcooling can be taken as $5^{\circ} \mathrm{C}$ respectively. In this study a MATLAB code is developed to compute the thermodynamic performance parameters of refrigerants at ARI conditions $\left(\mathrm{T}_{\mathrm{k}}=54.4^{\circ} \mathrm{C}\right.$ and $\left.\mathrm{T}_{\mathrm{e}}=7.2^{\circ} \mathrm{C}\right)$ respectively. The various performance parameters are refrigeration effect, compressor work, coefficient of performance, compressor discharge temperature, power per ton of refrigeration and volumetric cooling capacity.

The capacity and operating conditions of air conditioner considered in the present study for $\mathrm{R} 22, \mathrm{R} 407 \mathrm{C}$ and nineteen binary refrigerant blends are $\mathrm{Q}=1.5 \mathrm{TR}, \mathrm{T}_{\mathrm{k}}=54.4^{\circ} \mathrm{C}$ and $\mathrm{T}_{\mathrm{e}}=7.2^{\circ} \mathrm{C}$ respectively. The summary of results for the considered refrigerants are given in table 3 .

\section{Mathematical computations}

The mathematical computations involved in the thermodynamic analysis of for the considered refrigerants are given below.

Refrigerant mass flow rate is computed by

$$
\dot{m}=Q / R E
$$


Isentropic compressor work is computed as

$$
W_{c}=h_{2^{\mathrm{m}}}-h_{1^{\mathrm{m}}}
$$

Refrigerating effect (Cooling effect) is calculated as

$$
R E=h_{1^{n}}-h_{4^{n}}
$$

Coefficient of performance (COP) is calculated as

$$
C O P=R E / W_{c}
$$

Energy (Power) consumption by the compressor per ton of refrigeration is computed by

$$
P P T R=3.5167 / C O P
$$

Volumetric cooling capacity is calculated as

$$
V C C=\rho_{1^{\mathrm{m}}} \times R E
$$

The compressor discharge temperature $\left(\mathrm{T}_{\mathrm{d}}\right)$ is computed using superheated property tables and interpolating for the degree of superheat corresponding to the entropy difference.

Table 3. Summary of results for the various considered refrigerant blends

\begin{tabular}{|c|c|c|c|c|c|c|c|}
\hline $\begin{array}{c}\text { Refrigerant } \\
\text { code }\end{array}$ & $\begin{array}{c}\dot{m} \\
(\mathbf{k g} / \mathbf{m i n})\end{array}$ & $\begin{array}{c}\mathbf{R E} \\
(\mathbf{k J} / \mathbf{k g})\end{array}$ & $\begin{array}{c}\mathbf{W}_{\mathbf{c}} \\
(\mathbf{k J} / \mathbf{k g})\end{array}$ & $\mathbf{C O P}$ & $\begin{array}{c}\mathbf{T}_{\mathbf{d}} \\
\left({ }^{\mathbf{}} \mathbf{C}\right)\end{array}$ & $\begin{array}{c}\text { PPTR } \\
(\mathbf{k W} / \mathbf{T R})\end{array}$ & $\begin{array}{c}\mathbf{V C C} \\
\left(\mathbf{k J} / \mathbf{m}^{\mathbf{3}}\right)\end{array}$ \\
\hline 1 & 2.261 & 139.944 & 34.958 & 4.003 & 78.09 & 0.878 & 3646 \\
\hline 2 & 1.309 & 241.723 & 64.187 & 3.765 & 69.34 & 0.933 & 3560 \\
\hline 3 & 1.297 & 243.930 & 64.454 & 3.784 & 69.26 & 0.929 & 3553 \\
\hline 4 & 1.286 & 246.007 & 67.343 & 3.653 & 71.87 & 0.962 & 3543 \\
\hline 5 & 1.276 & 247.954 & 64.951 & 3.817 & 69.17 & 0.921 & 3524 \\
\hline 6 & 1.266 & 249.833 & 65.139 & 3.835 & 69.15 & 0.916 & 3508 \\
\hline 7 & 1.257 & 251.599 & 67.751 & 3.713 & 71.59 & 0.946 & 3494 \\
\hline 8 & 1.249 & 253.257 & 67.845 & 3.732 & 71.54 & 0.942 & 3479 \\
\hline 9 & 1.241 & 254.858 & 67.913 & 3.752 & 71.51 & 0.937 & 3464 \\
\hline 10 & 1.234 & 256.374 & 67.941 & 3.773 & 71.49 & 0.931 & 3451 \\
\hline 11 & 1.227 & 257.792 & 67.952 & 3.793 & 71.5 & 0.926 & 3437 \\
\hline 12 & 1.221 & 259.152 & 67.891 & 3.817 & 71.5 & 0.921 & 3426 \\
\hline 13 & 1.215 & 260.418 & 65.583 & 3.970 & 69.3 & 0.885 & 3414 \\
\hline 14 & 1.209 & 261.590 & 67.731 & 3.862 & 71.55 & 0.910 & 3405 \\
\hline 15 & 1.204 & 262.718 & 65.422 & 4.015 & 69.41 & 0.875 & 3394 \\
\hline 16 & 1.199 & 263.755 & 65.265 & 4.041 & 69.47 & 0.870 & 3385 \\
\hline 17 & 1.195 & 264.704 & 67.297 & 3.933 & 71.74 & 0.894 & 3376 \\
\hline 18 & 1.191 & 265.612 & 67.086 & 3.959 & 71.82 & 0.888 & 3367 \\
\hline 19 & 1.187 & 266.433 & 64.718 & 4.116 & 69.74 & 0.854 & 3356 \\
\hline 20 & 1.184 & 267.162 & 66.712 & 4.004 & 72.07 & 0.878 & 3338 \\
\hline 21 & 2.296 & 137.816 & 42.645 & 3.231 & 78.07 & 1.088 & 3172 \\
\hline
\end{tabular}




\section{Results and discussions}

The results and discussions of various performance parameters of R22, R407C and nineteen refrigerant blends (R290/R1270) are given below.

\subsection{Refrigeration effect}

Figure 2 shows the cooling effect (refrigeration effect) of various refrigerants blends. Referring to figure 2 it is noticed that refrigeration effect of nineteen refrigerant blends R290/R1270 (2 to 20) are higher than the R22 and R407C. This is due to high latent heat of vaporization of refrigerants when compared to R22 and R407C.

\subsection{Compressor work}

Figure 3 shows the work input required by the compressor for the various refrigerant blends. From the figure 3 it is observed that the compressor work of all the nineteen investigated refrigerant mixtures (2 to 20) are higher than the R22 and R407C. This is due to high vapour enthalpy of the refrigerant blends compared to R22 and R407C.

\subsection{Coefficient of performance}

Figure 4 shows the coefficient of performance of various studied refrigerants. COP is measured as an index of energy efficiency of the device charged with specific refrigerant. COP is the ratio of refrigeration effect to the compressor work. From the table 3 it is noticed that both cooling (refrigeration effect) effect and compressor work increase for all the nineteen investigated refrigerant blends. Therefore combined effect of cooling effect and compressor work of these refrigerants on coefficient of performance may be either increases or decreases or remains same which depends on the type and composition of the refrigerant blend and also on the working conditions of the device. From the figure 4 and table 3 it is clear that the COP of new binary refrigerant blend R290/R1270 (90/10 by mass $\%$ ) is $2.82 \%$ higher among R22, R407C and nineteen studied refrigerants.

\subsection{Compressor discharge temperature}

While introducing the new refrigerant blend into the equipment the consistency and lifespan of compressor motor should be studied. This can be achieved by computing the compressor discharge temperature of new refrigerants. Referring to figure 5 it is noticed that compressor discharge temperature of all the nineteen investigated refrigerants (2 to 20) are reduced by $6.0-8.90 \mathrm{C}$ when compared to $\mathrm{R} 22$ and $\mathrm{R} 407 \mathrm{C}$. This is due to lower adiabatic index of refrigerant blends. Hence all the nineteen studied fluids exhibits better reliability and lifespan of compressor motor.

\subsection{Power per ton of refrigeration}

Figure 6 shows the power (energy) spent by the compressor per ton of refrigeration for various studied refrigerants. It denotes the electrical energy required to the compressor to produce per ton of refrigeration. Referring to figure 6 it is observed that electrical energy spent by the compressor per ton of refrigeration for the refrigerant blend R290/R1270 $(90 / 10$ by mass \%) is $2.73 \%$ lower among R22, R407C and nineteen investigated 
refrigerants. This is due to type and composition of refrigerants and also due to operating conditions of the given device.

\subsection{Volumetric cooling capacity}

Figure 7 shows the volumetric cooling capacity of various refrigerant blends. Volumetric capacity depends on density of vapour refrigerant and cooling effect of the given fluid. It indicates the cooling capacity per unit volume of refrigerant vapour at the evaporator outlet. And also it denotes the volume of refrigerant handled by the compressor for the given fluid. From the figure 7 it is evident that volumetric cooling capacity of all the nineteen investigated refrigerants are closer to that of volumetric capacity of R22. Hence same size of compressor can be used for all the nineteen fluids as that of R22 with little modifications.

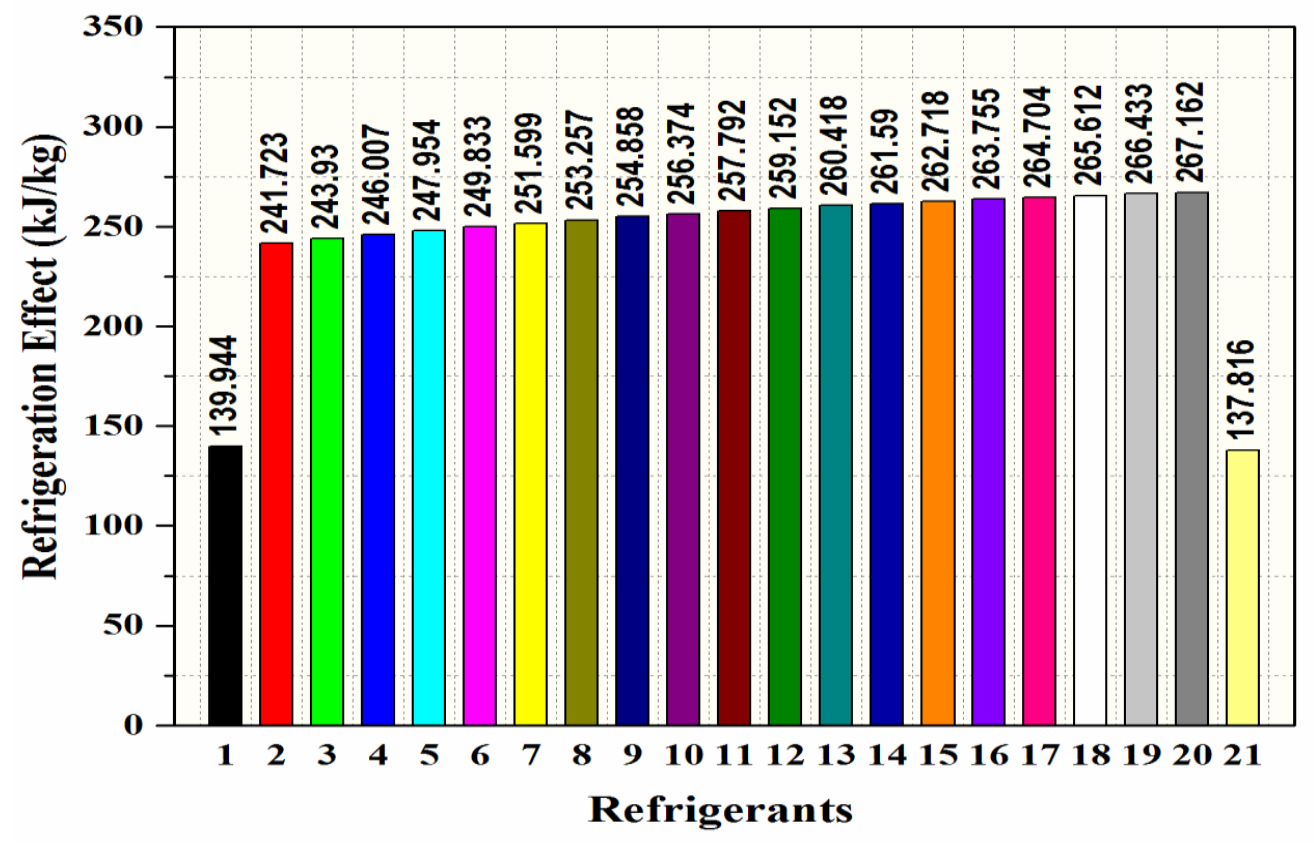

Fig 2. Refrigeration effect of various R22 alternative blends 


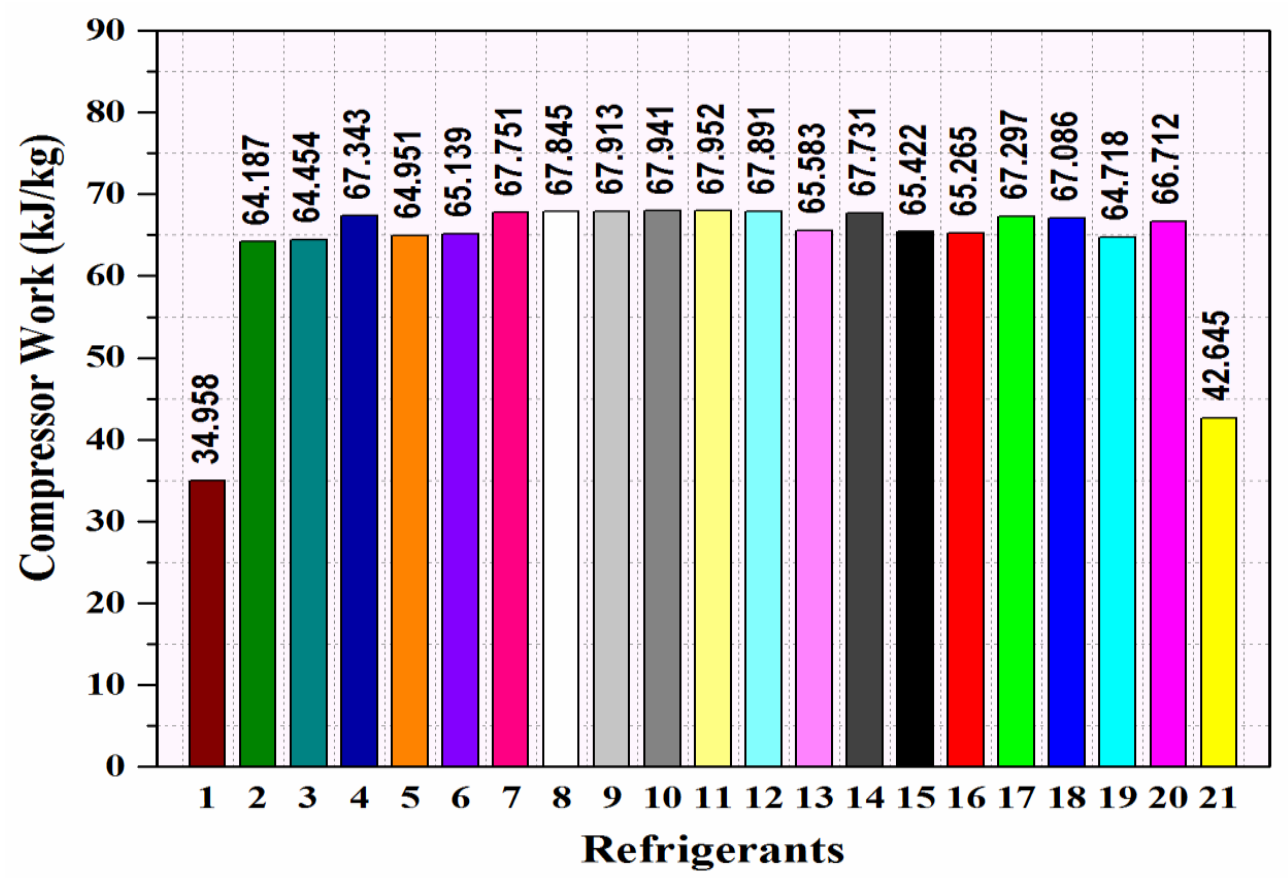

Fig 3. Compressor work of various R22 alternative blends

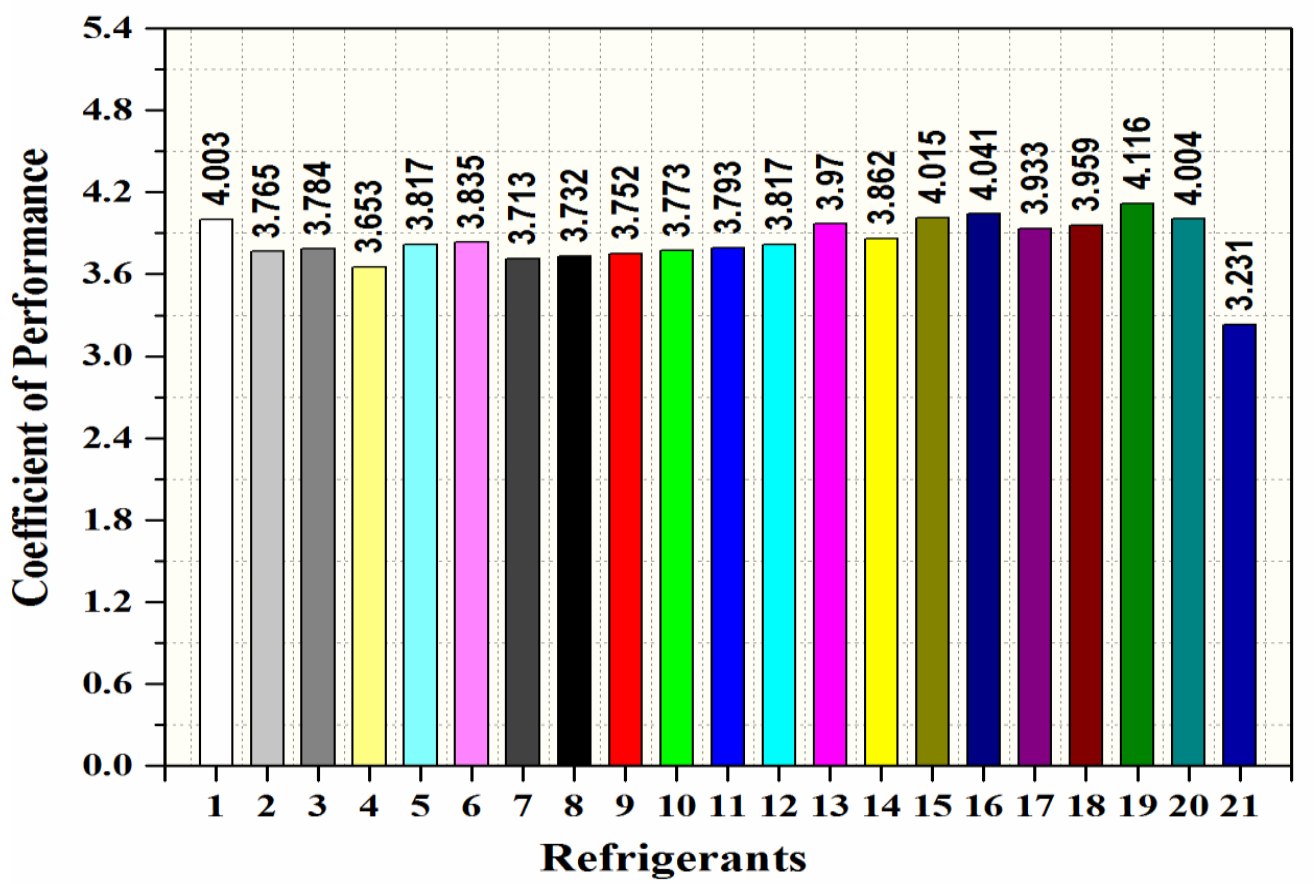

Fig 4. COP of various R22 alternative blends 


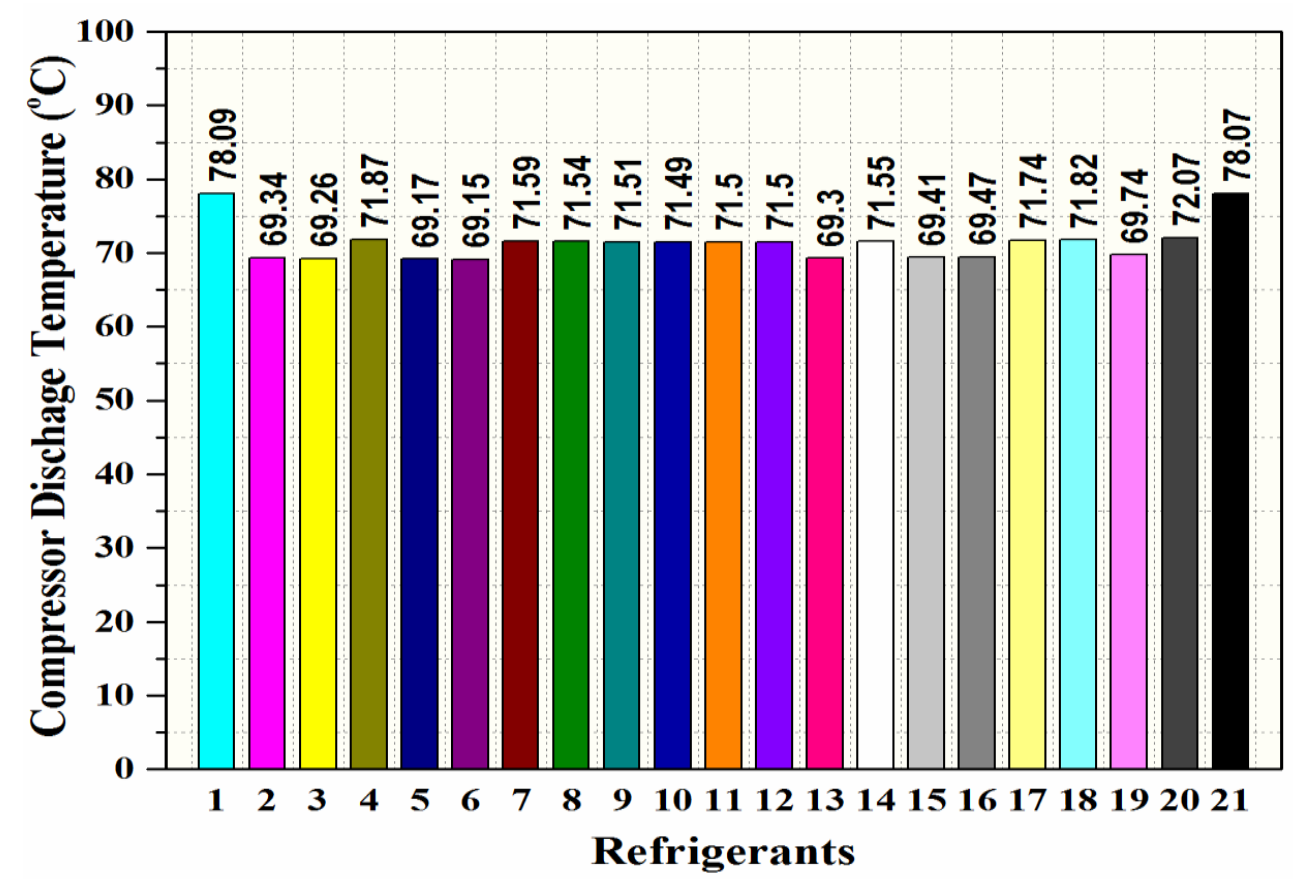

Fig 5. Compressor discharge temperature of various R22 alternative blends

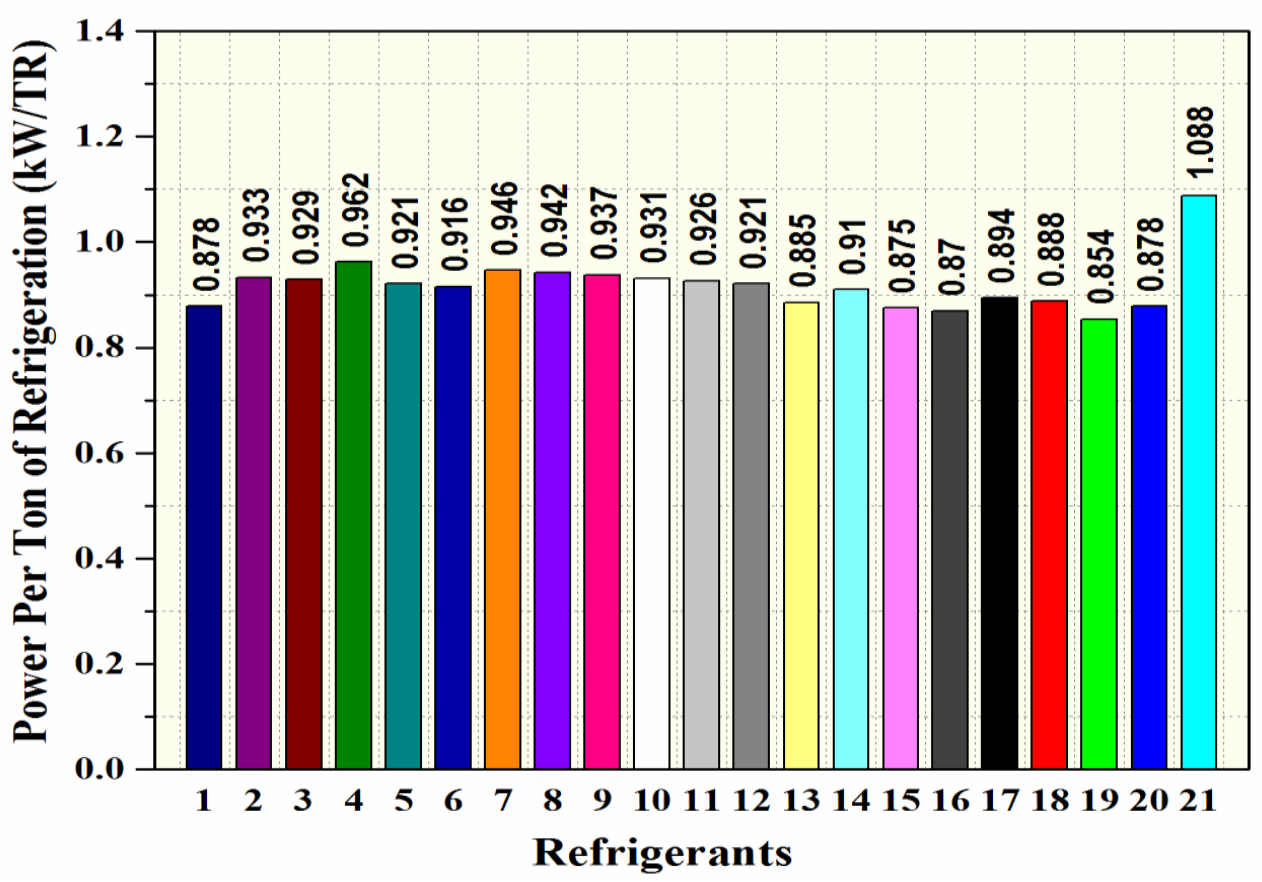

Fig 6. Power per ton of refrigeration of various R22 alternative blends 


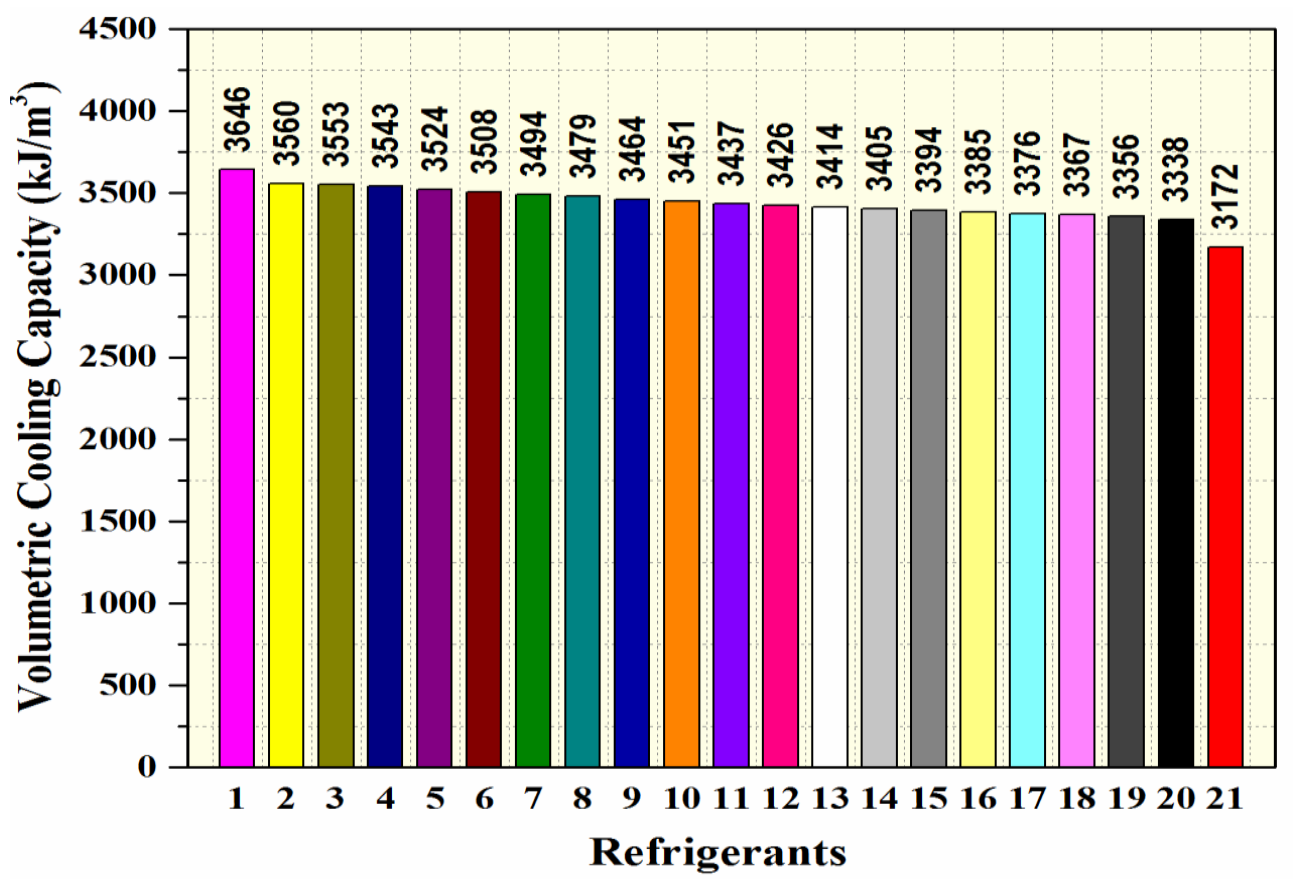

Fig 7. Volumetric cooling capacity of various R22 alternative blends

\section{Conclusions}

From the performance computation of various refrigerant blends the following conclusions can be drawn.

1. COP of new binary refrigerant blend R290/R1270 (90/10 by mass \%) was $2.82 \%$ higher among R22, R407C and nineteen studied refrigerants.

2. Compressor discharge temperature of all the nineteen refrigerant blends were reduced by $6.0-8.9^{\circ} \mathrm{C}$ compared to $\mathrm{R} 22$ and $\mathrm{R} 407 \mathrm{C}$. Therefore all the nineteen studied fluids would be advantageous from the standpoint of lifespan of compressor motor.

3. Energy (Power) spent by the compressor per ton of refrigeration for the refrigerant R290/R1270 (90/10 by mass \%) was 2.73\% lower among R22, R407C and nineteen studied refrigerants.

4. Volumetric cooling capacity of all the nineteen studied fluids were closer to that of volumetric capacity of R22. Hence same size of compressor can be used for all the nineteen refrigerants as that of R22 with very little modifications.

5. Overall thermodynamic performance of window air conditioner with R290/R1270 (90/10 by mass \%) was better than R22 with significant savings in energy consumption and hence it is an energy efficient sustainable refrigerant mixture as a drop in substitute to R22.

\section{Nomenclature}

ARI Air conditioning and refrigeration institute

GWP Global warming potential

ODP Ozone depletion potential

RE Refrigeration effect $(\mathrm{kJ} / \mathrm{kg})$

TR Ton of refrigeration $(\mathrm{kW})$
$\mathrm{P}_{\mathrm{c}} \quad$ Critical pressure (MPa)

Q Refrigeration capacity $(\mathrm{kW})$

$R \quad$ Universal gas constant $(\mathrm{J} / \mathrm{molK})$

$\mathrm{T}_{\mathrm{b}} \quad$ Boiling point $\left({ }^{\circ} \mathrm{C}\right)$

$\mathrm{T}_{\mathrm{c}} \quad$ Critical temperature (K)

$\mathrm{T}_{\mathrm{d}} \quad$ Discharge temperature $\left({ }^{\circ} \mathrm{C}\right)$ 


$\begin{array}{llll}h_{1^{a}} & \text { Enthalpy at the compressor entry }(\mathrm{kJ} / \mathrm{kg}) & \mathrm{T}_{\mathrm{e}} & \text { Evaporating temperature }\left({ }^{\circ} \mathrm{C}\right) \\ h_{2^{*}} & \text { Enthalpy at the compressor exit }(\mathrm{kJ} / \mathrm{kg}) & \mathrm{T}_{\mathrm{g}} & \text { Temperature glide }\left({ }^{\circ} \mathrm{C}\right) \\ h_{4^{*}} & \text { Enthalpy at the evaporator inlet }(\mathrm{kJ} / \mathrm{kg}) & \mathrm{T}_{\mathrm{k}} & \text { Condensing temperature }\left({ }^{\circ} \mathrm{C}\right) \\ \dot{m} & \text { Mass flow rate of refrigerant }(\mathrm{kg} / \mathrm{min}) & \boldsymbol{v} & \text { Specific volume }\left(\mathrm{m}^{3} / \mathrm{kg}\right) \\ M & \text { Molecular weight }(\mathrm{kg} / \mathrm{kmol}) & W_{c} & \text { Compressor work }(\mathrm{kJ} / \mathrm{kg})\end{array}$

\section{References}

1. United Nations Environmental Programme, Montreal Protocol on substances that deplete the ozone layer, Final act. New York: United Nations; 1987.

2. RL. Powell, J. Fluorine Chem, 114, 237-250 (2002)

3. M. Mohanraj, S. Jayaraj, C. Muraleedharan, Int. J. Greenh Gas Control 3, 108-119 (2009)

4. J.M. Calm, P.A. Domanski, ASHRAE J, 46, 29-39, (2004)

5. Atilla Gencer Devecioğlu, Vedat Oruc, j.egypro, 75, 1452-1457 (2015)

6. S. Devotta, A.V. Waghmare, N.N. Sawant, B.M. Domkundwar, Appl. Therm. Eng 21, 703-715 (2001)

7. S. Devotta, A.S. Padalkar, N.K. Sane, Int. J. Refrigeration, 28, 594-604, 2005.

8. X.H. Han, Q. Wang, Z.W. Zhu, G.M. Chen, Appl. Therm. Eng , 27, 2559-2565, (2007)

9. Ki-Jung Park, Dongsoo Jung, Appl. Energy, 86, 2598-2603, (2009)

10. B.O. Bolaji, Z. Huan, Renew. Sustainable Energy Rev, 18, 49-54, (2013)

11. Ki-Jung Park, Yun-Bo Shim, Dongsoo Jung, Energy Convers. Manage 50, 1671-1675, (2009)

12. Ki-Jung Park, Yun-Bo Shim, Dongsoo Jung, Appl. Therm. Eng, 29, 597-600, (2009)

13. Ki-Jung Park, Yun-Bo Shim, Dongsoo Jung, Appl. Energy, 85, 896-900, (2008)

14. Martin Joseph J, Yu-Chun Hou, AlChE J, 1, 142-151, (1955)

15. EW Lemmon, ML Huber, MO McLinden, "NIST Standard Reference Database 23, Version 9.1 Reference Fluid Thermodynamic and Transport Properties-REFPROP, National Institute of Standards and Technology, Standard Reference Data Program, Gaithersburg, (2013).

16. C P. Arora, Refrigeration and Air conditioning (Tata McGraw-Hill, New Delhi, 2009)

17. R.C. Arora, Refrigeration and Air conditioning (PHI learning Private Limited, New Delhi, 2010) 